\title{
Bases antropológicas para una fundamentación de los derechos humanos.
}

\author{
Rafael Santa María D’Angelo ${ }^{1}$
}

\begin{tabular}{ll}
\hline INFORMACIÓN DEL ARTÍCULO & RESUMEN \\
\hline Historia del artículo: & El reciente crecimiento en la comunidad internacional de los Derechos \\
Recibido el 23 de marzo de 2011 & Humanos lleva consigo la necesidad de reflexionar sobre su único \\
Aceptado el 15 de junio de 2011 & fundamento: el antropológico. Aspectos inherentes a la persona humana \\
& como la dignidad, la libertad y el amor nos muestran en sus conceptos y su \\
\hline Palabras claves: & sentido integral, elementos que superan la relativización (y sus \\
Persona humana & reduccionismos) del ser humano, y al mismo tiempo representan para el \\
Relativismo & derecho el horizonte a una mejor comprensión del fundamento y de su \\
Dignidad & sentido último. \\
Libertad & Caridad
\end{tabular}

Anthropological bases for a foundation of human rights

\section{Introducción}

"Todos los hombres desean la verdad", esta expresión referida por Aristóteles ${ }^{2}$, muestra que la aspiración natural de todo hombre por alcanzar la verdad se encuentra desde los orígenes mismos de la humanidad. La exhortación "conócete a ti mismo" esculpida sobre el dintel del templo de Delfos, mostraba la necesidad de responder a preguntas fundamentales como: ¿Quién soy?, ¿De dónde vengo?, ¿A dónde voy? Son interrogantes formuladas a todo hombre y en toda cultura.

Ciertamente la pregunta del hombre sobre sí no se limita a su propia individualidad, dado que estas cuestiones se universalizan, implica reconocer a la propia subjetividad como perteneciente a la naturaleza humana.
El hombre sigue siendo en gran medida un misterio, son vigentes las palabras de Sófocles cuando afirmaba que "muchas son las cosas misteriosas, pero nada tan misterioso como el hombre".

Para el cristiano, la cuestión acerca del hombre adquiere un lugar central, pues está enraizada a Dios, y sabemos por la Revelación que el hombre es "imagen y semejanza de Dios"4, y por consiguiente acceder al misterio del hombre es acceder al misterio de Dios, a través de su imagen en el hombre, fundamento de su inherente dignidad.

Ahora bien, esta reflexión en la actualidad viene dejada de lado por el relativismo imperante al negar toda referencia a la verdad, especialmente viene cegada la dimensión trascendente del ser humano por los reduccionismos antropológicos que se proponen,

\footnotetext{
${ }^{1}$ Abogado. Doctor en Derecho Universidad Lateranense, Roma. Profesor de la Facultad de Derecho de la Universidad Católica Santo Toribio de Mogrovejo, Chiclayo, Perú.

${ }^{2}$ ARISTOTELES, Metafisica, I.1

${ }^{3}$ SOFOCLES, Antífona, vv. 332- 333.

${ }^{4}$ Génesis, I, 26-27
} 
alejando cada vez más a la persona humana de su propia identidad.

Ante esta situación, urge reflexionar sobre la dignidad humana, sobre aquello que es y será siempre el valor intrínseco de todo ser humano, fundamento de todo derecho humano.

\section{ALGUNAS CONSIDERACIONES SOBRE EL RELATIVISMO}

El relativismo se entiende como la actitud intencional profunda que la conciencia contemporánea-creyente y no creyente-asume fácilmente con relación a la verdad ${ }^{5}$. El planteamiento relativista considera que en las realidades divinas y en el sentido profundo humano (personal y social), no existe una única vía para su conocimiento, pues todo queda condicionado a la historia, la cultura y la religión.

Expresando una parábola budista, el Card. Joseph Ratzinger, hoy S.S. Benedicto $X \mathrm{VI}{ }^{6}$, refiere a un rey que reunió a un número de ciegos qué no sabían lo que era un elefante. Uno tocó la cabeza, otro la trompa, otro la oreja, las patas. Cuando preguntó el rey a los ciegos sobre el elefante, cada uno daba diversas explicaciones sobre el animal, luego éstos comenzaron a discutir violentamente, llegando el punto de pelear físicamente, para deleite del rey, que a fin de cuentas era aquello deseado.

Este cuento ayuda a entender algunos planteamientos del relativismo. Primero, los hombres al querer absolutizar un conocimiento parcial seremos como los ciegos, inconscientes de nuestra intrínseca limitación. Segundo, al tomar esta posición, adquirimos un comportamiento violento e irrespetuoso, incompatible a la dignidad humana, al respeto, la tolerancia, y al final de cuentas, de la democracia.

Este razonamiento no parece darse cuenta que el relativismo hace posible la burla y el abuso de quien detenta el poder: en el cuento, el rey; sin embargo, en la actualidad, vienen representados por los que manejan el poder económico, político, ideológico, por medio de un manejo hábil, inescrupuloso de la opinión pública y de las otras expresiones del poder.

Para superar el relativismo, se debe pasar "desde la perspectiva teórica a la perspectiva ético- política...una

\footnotetext{
${ }^{5}$ RODRIGUEZ LUÑO ANGEL, Cultura, Política y Conciencia Cristiana. Ensayos de Ética Política. RIALP Madrid 2007. Pp. 179

${ }^{6} \mathrm{Cfr}$. RATZINGER CARD. JOSEPH, Fe, Verdad y Tolerancia. Ediciones Sígueme, Salamanca 2008., pp. 143

7 RODRIGUEZ LUÑO ANGEL, Op. Cit., Pp. 188-189. "Negar el principio moral, impugnar ese órgano de conocimiento- previo a cualquier especialización- que llamamos conciencia, significa negar
}

cosa es la relación de la conciencia con la verdad, y otra bien distinta es la justicia de las personas"".

De esta lógica, una afirmación especulativa, que intenta decir cómo son las cosas, sólo las puede decir de modo verdadero o falso. Para otras apreciaciones (la estructura del Estado, la forma de gobierno, la concepción de los derechos civiles), se podría decir que cabe otra valoración de justo o injusto, liberal o conservador.

"Ciertamente, no hay un único modelo de organización política y económica de la libertad humana, ya que culturas diferentes y experiencias históricas diversas dan origen, en una sociedad libre y responsable, a diferentes formas institucionales. Pero una cosa es afirmar un legítimo pluralismo de "formas de libertad", y otra cosa es negar el carácter universal o inteligible de la naturaleza del hombre o de la experiencia humana. Esta segunda perspectiva hace muy difícil, o incluso imposible, una política internacional de persuasión..."

Vemos como esta corriente relativista tiende a dudar y a desconocer conceptos básicos, entre éstos el de la propia naturaleza y dignidad humana, considerando inalcanzable su conceptualización.

$Y$ es que "...poner en el centro el tema de la verdad no es un acto meramente especulativo, restringido a un pequeño círculo de pensadores; al contrario, es una cuestión vital para dar profunda identidad a la vida personal y suscitar la responsabilidad en las relaciones sociales (cf. Ef. 4, 25). De hecho, si no se plantea el interrogante sobre la verdad y no se admite que cada persona tiene la posibilidad concreta de alcanzarla, la vida acaba por reducirse a un abanico de hipótesis sin referencias ciertas..."

\section{EL PROBLEMA DEL REDUCCIONISMO ANTROPOLÓGICO}

La aproximación al ser humano si bien es un misterio, sin embargo, existe una precomprensión orientadora, precomprensión del hombre, que durante años ha sabido reconocer en toda persona dimensiones inseparables dentro de su unicidad biológica-sicológica-

al hombre". RATZINGER CARD. JOSEPH, Verdad, valores y Poder, Piedras de toque de la sociedad pluralista. Rialp. Segunda Edición. Madrid 1998. Pp. 31.

8 JUAN PABLO II, Discurso a la Quincuagésima Asamblea General de las Naciones Unidas, Nueva York, 5 de octubre de 1995. (el énfasis es nuestro)

${ }^{9}$ BENEDICTO XVI, Discurso en la visita del Santo Padre a la Pontificia Universidad Lateranense, 21 de octubre de 2006. 
espiritual $\left.\right|^{10}$. Si el sentido común y el lenguaje ordinario nos sugieren la similitud de los términos "persona" y "ser humano", acompañada de una reflexión habituada a concebir la persona como caracterización apropiada de lo humano. En nuestros días por los recientes avances científicos a nivel de la biomedicina y el bioderecho, no es muy sencillo identificar o asociar el significado de estos términos.

No pocos en la actualidad al referirse a la "persona" consideran que no significa "ser humano" y viceversa ${ }^{11}$. Separada de sus raíces, la noción de persona asume hoy nuevos roles que ponen en peligro su propio valor, intuitivo y originario. Luego de los fenómenos discriminatorios referidos, nos enfrentamos ahora a una nueva forma de exclusión humana más sutil, por el grado de desarrollo físico, psíquico y social del ser humano, que específicamente ataca los casos confines: la discriminación contra los embriones, los fetos, los niños, los discapacitados, los ancianos, los enfermos incurables.

Entre algunas visiones reduccionistas destacan el dualismo, el utilitarismo y el sociobiologismo ${ }^{12}$.

\subsection{Dualismo}

Con esta visión reduccionista se separan los conceptos de ser humano y persona humana.

La persona viene reconocida como el sujeto desencarnado, titular de los derechos, en cuanto capaz de luchar por ellos. El ser humano no persona, al ser simplemente cuerpo biológico, carece de derechos y puede ser sometido como objeto al experimento genético, o a la biotecnología.

${ }^{10} \mathrm{Cfr}$. LUCAS LUCAS RAMON, El hombre, espíritu encarnado. Compendio de filosofía del hombre. Editorial Sígueme. Salamanca 2005. Pp. 8-25. Así, una visión integral al ser humano debe comprender tres realidades que interactúan dentro de la unicidad de su ser. Un aspecto biológico que muestra un cuerpo físico que se va desarrollando desde la concepción hasta la muerte natural; un aspecto psicológico que muestra el lado racional del hombre, la inteligencia; y por último y no por ello el menos importante, un aspecto espiritual, que dota al ser humano en su esencia más íntima, aquello que lo remite a su anhelo de infinito y de trascendencia. Ser humano pues, como unidad bio-sico-espiritual. ${ }^{11}$ Esta no es la primera vez que la reflexión racional y la experiencia concreta muestran la separación entre persona y ser humano. Bastaría hacer referencia a la esclavitud, el racismo, a la persecución judía, por mencionar algunas en las cuales no era negada la pertenencia biogenética a la especie humana, sino el reconocimiento ontológico de persona, y como tal su relevancia ética y jurídica. Cfr. PALAZZANI LAURA, Introduzione alla Biogiuridica. Giappichelli Editore. Torino 2002. Pp. 21-42.

12 Esta clasificación es desarrollada por BALLESTEROS JESUS, Exigencias de la dignidad en la biojurídica BALLESTEROS JESUS-
De este modo un presupuesto para el reconocimiento de la condición de persona, y por tanto para ser titular de derechos, es la conciencia y la capacidad de elección. Según el dualismo, la naturaleza no viene considerada, pues únicamente es la cultura, expresada como técnica o dominación de la naturaleza, la que crea derechos. Si es la autonomía la que atribuye derechos, se niega éstos y se niega dignidad a los seres no autoconscientes: como los embriones, fetos, niños pequeños, enfermos mentales y terminales.

Este dualismo presentado en la actualidad no resulta un conflicto social más, sino que atañe a toda la humanidad la cual no queda reconocida sino más bien seleccionada, y seleccionada ¿ante los ojos de quién?, ¿a título de qué?; un nuevo eugenismo se proyecta discriminando con ello al mismo ser humano ${ }^{13}$.

Un aspecto que resulta importante distinguir en el ser humano es el nivel ontológico y el nivel operativo, es decir, el plano del ser y el del actuar. Si primero es el ser, y de ahí deriva el actuar, habrá que tener en cuenta cual es el ser, la ontología de una realidad, para calificar su realidad. Puede darse que un ser no esté actuando por determinadas causas, por ejemplo, el sueño, y no por eso deja de tener unas características ontológicas.

En este sentido es de considerar que "el valor del ser humano no queda condicionado por la adquisición de determinados atributos, pues a quien hay que defender es al hombre sin atributos" 14 .

\subsection{Utilitarismo}

Coincide con el dualismo en cuanto a afirmar que no todo ser humano es considerado persona humana, sin

APARISI ANGELA (eds.), Biotecnología, dignidad y derecho: bases para un diálogo. EUNSA. Pamplona 2004. Pp. 44- 57.

${ }_{13}$ Cfr. PALAZZANI LAURA, /I concetto di persona tra bioetica $e$ diritto, G. Giappichelli, Torino 1996., pp. 31 -38. “...De acuerdo con una concepción bien fundada filosóficamente desde el punto de vista de la tradición, es persona todo ser de una especie cuyos miembros poseen la capacidad de alcanzar la autoconciencia y la racionalidad. Por tanto, si sólo fueran personas aquellos seres que, en efecto, poseen dichas cualidades en acto, en ese caso a cualquier hombre dormido podría serle impedido despertar vivo, pues mientras duerme, claramente no es persona. El deber de proteger su vida -cuando se queda dormido sin el temor de no volver a despertar ya nunca- cesa, en todo caso, según nuestros deseos..." SPAEMANN ROBERT, ¿Son todos los hombres personas? Cuadernos de Bioética 31, 3o Grupo de Investigación en Bioética. Santiago de Compostela 1997, Pp. 1030-1033

${ }^{14}$ SANTA MARIA D’ANGELO RAFAEL, El Diagnóstico prenatal de los discapacitados y la tutela de los derechos fundamentales. Diálogo con la Jurisprudencia № 116. Editorial Gaceta Jurídica. Lima 2008., pp. 172 
embargo, añade algo más, niega la diferencia entre un ser humano y un animal.

Según el utilitarismo: el elemento decisivo para ser persona y titular de derechos es el ser capaz de placer y/o sufrimiento, y ello es común a seres humanos (pero sólo algunos) y animales (pero sólo algunos); el utilitarismo aproxima al ser humano y al animal.

De esta forma un animal, pensemos en un caballo o un perro con algunos años es un animal más sociable y razonable, puede sentir y sufrir más que cualquier recién nacido. Por ello se propone ampliar el número de titulares de derechos. Éstos pasan a ser ahora todos los capaces de gozar y de sufrir (entre ellos los animales, especialmente los simios) $)^{15}$.

Uno de los principales representantes de esta corriente es Peter Singer, quien sostiene que es conveniente establecer prioridad de ciertos animales sobre ciertos seres humanos, en este sentido expresa: "no hay razón para matar chimpancés antes que a niños anencefálicos"16.

Para el utilitarismo al criterio definitivo es la eliminación de todo sufrimiento como algo indigno, legitimando en este sentido la manipulación genética, la eutanasia, pues antes de sufrir es preferible morir.

A este utilitarismo se puede responder que la presencia de una función (el ser capaz de placer y/o sufrimiento), presupone la existencia de un sujeto, de un sujeto con una naturaleza determinada que hace posible el ejercicio de aquella función, y que es la capacidad de tener esta función y no su ejercicio, aquello que constituye al ser y la natura de un sujeto. Las funciones no son el sujeto si nunca revelan al sujeto y su naturaleza, la manifiestan.

Si la persona se redujese a un conjunto de características o funciones que aparecen y desaparecen en los diversos individuos y en diversas situaciones, tendríamos para reconocer a una persona que valorar caso por caso. ${ }^{17}$

Frente a la tesis central del utilitarismo, que niega la dignidad a la vida que sufre, es conveniente entender que la dignidad del ser humano se expresa de un modo más luciente en el sufrimiento y en el dolor.

\footnotetext{
15 Ver http://www.proyectogransimio.org/index.php (fecha de revisión: 07/05/11)

${ }^{16}$ SINGER PETER, Repensar la vida y la muerte. El derrumbe de nuestra ética tradicional. Paidós. Barcelona 1997. Pp. 99 cit. BALLESTEROS JESUS, Op. Cit. Pp. 49

17 Cfr. PALAZZANI LAURA, Persona, Bioetica e Biogiuridica. Medicina e Morale. Rivista Internazionale di Bioetica. Centro di Bioetica. Facoltà di Medicina e Chirurgia Agostino Gemelli.Università Cattolica del Sacro Cuore. Roma. 2004/2. Pp. 312.
}

\subsection{Sociobiologismo}

Por la que se discrimina genéticamente a los seres humanos. Según esta visión reduccionista, fundada en una interpretación determinista de la genética, el ser humano se reduce a genoma. La persona humana queda considerada como una especie animal más, permitiendo así el desarrollo de la ingeniería genética.

De acuerdo a esta perspectiva eugenésica, se da énfasis a la importancia de la herencia como factor central de la inteligencia y del comportamiento humano, restando la influencia del medio.

A diferencia del dualismo y utilitarismo, la sociobiología rompe de un modo más radical la unidad de la especie humano al diferenciar entre seres humanos bien nacidos con un correcto genoma, y no bien nacidos, que podrían ser susceptibles de manipulación o eliminación. Lo que se pretende es la supervivencia de los genes más complejos, sofisticados y fuertes, de este modo el sujeto deja de ser el hombre para convertirse en el gen.

Una práctica que demuestra este tipo de visión es el diagnóstico preimplantatorio, que por un lado descarta los embriones que presentan alguna deficiencia, y por otro, busca mejorar la "calidad" de los niños, asegurando unos genes "óptimos".

A esto conviene recordar que "la realidad del ser humano, a través de toda su vida, antes y después del nacimiento, no permite que se le atribuya ni un cambio de naturaleza ni una gradación de valor moral, pues muestra una plena cualificación antropológica y ética. El embrión humano, por lo tanto, tiene desde el principio la dignidad propia de la persona"18.

\section{DIGNIDAD DE LA PERSONA HUMANA, LIBERTAD Y DERECHO}

Referirse a la dignidad humana ${ }^{19}$ no es sencillo, pues la crisis de los valores es hoy la crisis del hombre, que no reconoce su dignidad personal, y por eso, no respeta la dignidad de los demás.

El tema de nuestro tiempo es radicalmente un asunto antropológico. Es fundamental, por ello, desarrollar toda una referencia a la dignidad humana que establezca primordialmente el valor de su finalidad, respecto al conocimiento (especialmente el jurídico),

18 CONGREGACION PARA LA DOCTRINA DE LA FE, Instrucción Dignitas Personae. Sobre algunas cuestiones de Bioética, 5.

${ }^{19}$ La palabra dignidad deriva del latín dígnitas, en referencia al alto grado, a la majestad y decoro de la persona. Significa la nobleza que el hombre tiene por su propia naturaleza. Este significado se complementa con el vocablo dignus que deriva del verbo decet ("es conveniente") y significa "que conviene a", "digno de", "merecedor". De dignus se derivan otras palabras como dignitas ("mérito", "dignidad", "alto rango") o indignus o condignus. 
consciente que el ser de la persona es la primera fuente de dignidad humana.

La visión coexistencial del derecho permite precisamente responder a este propósito, conforme veremos a continuación.

\subsection{Dignidad humana: de lo ontológico a lo moral.}

Esta problemática de los reduccionismos nos muestra la exigencia actual que el hombre para ser considerado como tal, y por tanto digno, debe demostrar algunas cualidades.

Refiere D'Agostino: “.... no queda en línea de principio que hipotizar que el reconocimiento de la identidad personal de un sujeto debe depender únicamente de su pertenencia objetiva a la especie humana... la dignidad personal puede depender sólo de la casualidad del nacimiento como seres humanos, casualidad que debe ser garantizada como jurídicamente indisponible.... es indispensable, para garantizar el carácter humano de la convivencia, que a la categoría de persona venga asociada la idea de un status de inviolabilidad; y este status debe ser antecedente no solo a la posibilidad de ejercitar derechos, sino también a aquella de individuarlos y determinarlos..." 20

Queda claro pues, que no existe una gradualidad en la persona, no se es más o menos persona. Se es o no es persona, y la dignidad pertenece al sujeto de esta natura por el mero hecho de ser sujeto de ésta. Esto además queda evidenciado cuando descubrimos, muchas veces sólo a nivel pre-consciente, un profundo e inexorable impulso a que seamos tratados como "alguien" y no como "algo". Todo nuestro ser se rebela ante la posibilidad de ser instrumentalizados por otros $^{21}$.

Pues bien, este dinamismo interior de autodefensa del "yo", como sujeto y no como objeto, apunta hacia la existencia de nuestra dignidad. Una dignidad que no está condicionada a ninguna instancia exterior o no

\footnotetext{
20 "antes de indicar los especificos derechos y los específicos deberes de cada jugador, es necesario presuponer que ninguno entre ellos tenga o se confiera el derecho de establecer en modo apriorístico, unilateral e irreversible a quien está consentido ser admitido al juego (social), y quien deba en cambio quedar excluido" D'AGOSTINO FRANCESCO, Parole di bioetica, G.Giappichelli Editore. Torino 2004. Pp.152-153 (traducción personal, el enfasis es nuestro)

${ }^{21}$ Kant tenía razón cuando dijo: "Nunca trates a los demás como meros medios, sino como fines en ellos mismos". KANT I. Fundamentación de la metafísica de las costumbres. Real Sociedad Matritense de Amigos del País. Madrid 1992. Pp. 73.

22 "Todo hombre es esencialmente persona, siempre y en cualquier circunstancia o etapa de su vida es persona. Ya sea en el seno materno, en la infancia, al final de su vida; ya sea en una situación
}

esencial, como el rango social o económico, la raza, la salud, etc. La persona humana vale por el mero hecho de ser persona y no por ésta o aquélla de sus características accidentales. Nuestro sentido de ser finen-nosotros-mismos es una poderosa indicación de esta verdad $^{22}$.

La dignidad humana más que un valor, es un rasgo de la condición humana de carácter objetivo, real, un primer principio, fuente de todos los derechos, con carácter basilar, no disponible, que acompaña a todo ser humano, por el sólo hecho de ser un individuo de la especie ${ }^{23}$.

Ahora bien, es importante reconocer la distinción entre dignidad ontológica y la dignidad moral. La primera es constitutiva y está presente en el ser humano desde su concepción, nunca se pierde, lo acompaña hasta la muerte. La dignidad moral, que se relaciona directamente con la libertad, estimula a toda persona a vivir acorde a nuestra condición, de ser "alguien", un comportamiento adecuado a su naturaleza.

Si bien todos los hombres participan de la misma dignidad ontológica, no todos tienen la misma dignidad moral: ésta depende de la adecuación de la conducta a las exigencias éticas del estatuto personal. Pero, en ningún caso, la dignidad depende de los condicionamientos externos: ni en el plano ontológico ni en el moral. Esta distinción es fundamental para preservar la inviolabilidad del respeto debido a la dignidad humana.

Se entiende que la dignidad humana no es simple autonomía moral, pues cuando la libertad se concibe como simple capacidad de autodeterminación, su fundamento $y$, de algún modo, su contenido, dejan de ser heterónomos, para convertirse en autónomos y, en esa medida, vulnerables, porque se incurre en una tautología, que hace depender la dignidad del consenso o de la arbitrariedad y, en esa medida, pierde su carácter universal e inviolable ${ }^{24}$.

de menor integridad física, moral o intelectual; ya sea en una condición de pobreza, física o cultural; ya sea en cualquier momento de la vida humana. Todos los hombres tienen una idéntica y permanente dignidad, que se deriva del hecho natural de que son personas, de pertenecer a la especie humana". VILA CORO MARIA DOLORES, Op. Cit., Pp. 156. F. FORMENT, Los cuidados de enfermería: Cuadernos de Bioética. Núm. 12-44. Grupo de investigación de Bioética, Santiago de Compostela 1992. p. 55-56.

${ }^{23}$ Conforme se expresa en la Constitución del Perú en el art. 10: "La defensa de la persona humana y el respeto de su dignidad son el fin supremo de la sociedad y del Estado".

${ }^{24}$ Cfr. PACHECO ZERGA LUZ, "La dignidad humana en la Declaración Universal de los Derechos Humanos". AAVV. 60 años de la Declaración Universal de los Derechos Humanos. Universidad Católica Santo Toribio de Mogrovejo. Chiclayo 2008., pp. 9-30. 
Como vemos esta doble dimensión de la dignidad humana nos remite hacia la libertad, sin la cual no se podría entender a la primera, de allí su relación indesligable.

\subsection{Libertad, verdad y amor}

Referirse a estos puntos, ya por separado nos llevaría en su reflexión enteras tesis. No obstante, trataremos escuetamente de proponer una síntesis que permita integrar estos tres conceptos: libertad, verdad y amor. Empezamos refiriéndonos a la libertad. No cabe duda, que para el hombre de nuestro tiempo la libertad se manifiesta como el bien más elevado. De hecho en el común de las personas, la primera idea sobre ésta, viene referida a no estar obligados por ningún agente externo, a toda ausencia de coacción ${ }^{25}$.

De otra parte, la libertad es vista desde una "autoposesión" o dominio de los propios actos, que implica la responsabilidad de nuestras acciones, la que acompaña y proyecta a la persona en el tiempo, por eso somos capaces de realizar y cumplir promesas.

Esta experiencia de libertad, que en menor o mayor medida cada uno la descubre en su vida cotidiana, no resulta suficiente, es decir no basta la mera "sensación de libertad" para entender qué es ésta, tenemos que profundizar más en la reflexión, por ello es necesario dar un paso adicional hasta alcanzar la dimensión metafísica de la libertad humana.

Es claro que un mayor entendimiento sobre la libertad, nos remite necesariamente a una consideración de la persona humana, la que por su propia naturaleza y unidad está llamada a la perfección.

La libertad así resulta una realidad trascendental, uno de los rasgos específicos de la persona humana. Una libertad constitutiva, inscrita en todo ser humano de manera originaria por el mero hecho de ser persona. No se quita ni se adquiere nunca, es natural ${ }^{26}$.

Esta libertad nos muestra, al tratarse de la libertad de la persona humana, una libertad finita, es decir situada en el tiempo, y por tanto limitada. ${ }^{27}$ Sin embargo, es en la libertad trascendental que la persona humana toma conciencia que puede encaminar su vida hacia su propia

\footnotetext{
25 Para muchos la libertad viene entendida como el derecho de hacer simplemente todo lo que se desee y no tener que hacer cosa alguna que no se desee.

${ }^{26} \mathrm{Es}$ interior y guarda apertura a todo lo real con una amplitud enorme de posibilidades, que deriva de la infinitud de nuestros pensamientos y de la voluntad.

${ }^{27}$ Esto se entiende, pues la vida humana continuamente nos muestra que hay cosas que escapan al poder de la voluntad: el hombre, al inicio, no puede elegir su situación histórica ni cultural,
}

realización, no de "crearse" a sí mismo a partir de la nada, sino de "hacerme a sí mismo" a partir de la naturaleza humana recibida.

Los argumentos antes mencionados nos ayudan a ir interiorizando en la reflexión sobre la libertad. Ciertamente, la libertad trascendental evidencia claramente que toda persona humana nace con libertad, ésta en el tiempo se va desplegando a través de elecciones continuas, que muestran en el actuar la autonomía de la voluntad.

Ahora bien, es propio sobre esta libertad de elección que conviene reflexionar. La voluntad, presupuesto fundamental de toda elección, es una propiedad mediante la cual la persona humana se autodetermina hacia aquello que la inteligencia le presenta como bueno. En toda acción el hombre busca necesariamente el bien, bien desde una perspectiva general y no concreta.

Por la universalidad de la ley natural, todo hombre nace con la rectitud necesaria de razón para conocer el principio de hacer el bien y evitar el mal, pues "... es propio de la libertad la capacidad de la conciencia para percibir los valores humanitarios fundamentales que atañen a todos los hombres..." 28 .

No obstante, en la actualidad esto no parece entendido, quizás por desinterés o ignorancia, o tal vez por una intencional exacerbación a la autonomía de la voluntad. En este sentido, algunas concepciones modernas de libertad no aceptan el vínculo entre voluntad y bien. En ellas se entiende libertad como sola indeterminación o indiferencia hacia determinados fines. Ser libre es estar indeterminado. De este modo, la libertad es entendida como un fin en sí mismo, y no como una posibilidad para alcanzar el bien por sí mismo.

El riesgo de esta interpretación es que, la autonomía niegue la naturaleza humana, el hombre al no tener naturaleza, sería para sí mismo su propio proyecto de existencia ${ }^{29}$. Este presupuesto de "sin sentido" de la libertad, de un hombre condicionado a la frustración, nos presenta la necesidad de una reflexión que vaya a más, que supere esta confusa y unilateral percepción de libertad alejada de la esencia y verdad del

la libertad está situada en el tiempo: es algo que viene dado, no elegido.

${ }^{28}$ RATZINGER CARD. JOSEPH, Verdad, valores y Poder, Op. Cit., pp. 34.

${ }^{29} \mathrm{Al}$ ser la esencia del hombre indeterminada y no tener naturaleza y ser solamente libertad, se manifiesta a un individuo que procura vivir su existencia con una profunda frustración en la vida, con un vacío existencial donde el hombre se vuelve en un ser sin sentido. 
ser humano, pues claramente no se puede entender realmente a la libertad sin verdad.

Una idea que debe quedar clara es que la libertad no hace al hombre, no le da su ser; la persona existe y se desarrolla por y en el ser del hombre. Esto ayuda a entender a la libertad contenida en el ser humano, quien tiene una naturaleza libre y sin esta naturaleza no habría libertad. Gracias a la naturaleza humana la libertad encuentra su sentido y su cauce.

Se debe además entender la libertad aunada al bien, a la verdad, supone entender que éstas no pueden estar condicionadas ni al consenso, pues el consenso no es sinónimo de verdad, ni a la autonomía absoluta y tampoco a la autosuficiencia de la razón.

Es por ello que, entendida la libertad dentro da la unidad que representa la persona humana, resulta oportuno referirse a ésta como autodeterminación al bien. Más que la sola capacidad de elegir se entiende a la libertad como la capacidad de autodeterminarse al bien. La libertad no se entiende como pura indeterminación, indiferencia o mera autonomía de la voluntad, puesto que ésta siempre hace referencia al bien (la verdad) presentado por el entendimiento.

Por eso la necesidad del buen uso de la libertad de elección que se entiende y fortalece en la virtud. La libertad se va conquistando, ganando en el día a día y realizando así un proyecto de vida. Así la libertad se hace virtud gracias al señorío de uno mismo, lo que en otras palabras sería la dignidad moral ${ }^{30}$.

Sin embargo, nos interesa agregar algo a esta reflexión. Visto que la libertad orientada al bien perfecciona a la persona, la encamina hacia su propia realización y despliegue personal (demostrando así la verdad misma de la persona); Esto resulta insuficiente sino se integra $y$ ahonda en el amor.

En el contexto actual hablar de amor resulta confuso, aquello que se designa generalmente tiene como punto de referencia una suerte de sentimentalismo difuso y superficial. No cabe duda, que este olvido o simplemente indiferencia del significado de amor

\footnotetext{
${ }^{30}$ Es por ello que un aspecto importante de la libertad consiste en la educación de las tendencias naturales, que no es sólo la capacidad de elegir un proyecto de vida, sino de realizarlo efectivamente. Justamente es libertad ya que supone el autodominio sobre esas tendencias. Algunos autores explican muy bien esto con el ejemplo del pianista y el deportista. Ambos para realizar su oficio con perfección realizan horas de entrenamiento, práctica y van logrando junto al esfuerzo, sacrificio y disciplina cotidiana sobresalir. Así la persona humana que entiende el valor de la libertad, la forja gracias a la voluntad y la demuestra con buenas acciones.

${ }^{31}$ Es por ello que un aspecto importante de la libertad consiste en la educación de las tendencias naturales, que no es sólo la
}

representa uno de los males de fondo de nuestra sociedad y de nuestra cultura.

Una definición clásica del amor, es aquella que refirió Aristóteles en su Retórica, quien nos dice que amar es "querer el bien para otro en cuanto otro"31.

Esta sintética reflexión del amor, brinda a la libertad un profundo significado, pues como autodeterminación la libertad implica un querer; como autodeterminación al bien la libertad implica reconocer lo bueno y verdadero no sólo para uno mismo, sino también para el otro, y finalmente el sentido de real libertad se entiende mejor cuando la ofrece al servicio del otro (de la persona amada), de los demás, aquí complementa la definición del Estagirita al señalar que amar es querer el bien para otro en cuanto otro.

Ahora bien, estos presupuestos no son ajenos a una reflexión jurídica. Según Cotta ${ }^{32}$, si consideramos la caridad como deber moral, es más simple su relación con la moralidad del Derecho. Primero, porque el sujeto situado desde la perspectiva de la caridad tiene el deber de amar en conciencia, a cualquier persona y en todo; pero no tiene el derecho de recibir como contraprestación, como acontece con la relación jurídica, donde se da la correspondencia entre el deber y derecho.

Luego, reconociendo que la justicia constituye lo trascendental del derecho, la cual propiamente en una relación jurídica a partir del reconocimiento de la paridad ontológica de los sujetos sirve al Derecho para establecer o restablecer, por razón de Justicia, una medida igualitaria para los sujetos sobre el plano de sus respectivas acciones, y a determinar su propia responsabilidad personal ante el incumplimiento de tal medida.

Precisamente esa paridad ontológica vista desde la Caridad porta a la aceptación total del otro, independientemente de sus posibles derechos y obligaciones, de sus méritos y deméritos, con atención hacia él, de dar o perdonar, fuera de toda medida de Justicia. Esta es la característica ultra-medida propia de

capacidad de elegir un proyecto de vida, sino de realizarlo efectivamente. Justamente es libertad ya que supone el autodominio sobre esas tendencias. Algunos autores explican muy bien esto con el ejemplo del pianista y el deportista. Ambos para realizar su oficio con perfección realizan horas de entrenamiento, práctica y van logrando junto al esfuerzo, sacrificio y disciplina cotidiana sobresalir. Así la persona humana que entiende el valor de la libertad, la forja gracias a la voluntad y la demuestra con buenas acciones.

32 Cfr. COTTA SERGIO, Itinerarios Humanos del Derecho. EUNSA. Segunda Edición. Pamplona 1978., pp. 100-102. 
la Caridad, la que transforma en total tanto por su profundización y por su capacidad universal de aceptación de los otros, de esto se comprende la supremacía de la Caridad sobre todas las otras formas de vida moral.

\subsection{La dignidad de la Persona humana y el derecho}

Para preservar una visión integral del ser humano, es necesario considerar con claridad que todo ser humano es persona, el ser humano, hombre o mujer, es una persona.

Como se ha referido anteriormente, la reflexión sobre la persona humana en la actualidad exige: comprender que existe un primado en la definición de la naturaleza sobre la función, no una gradualidad en la persona. La persona humana vale por el mero hecho de ser un ser humano y no por ésta o aquélla de sus características accidentales.

Estos presupuestos nos ayudan a introducirnos en una reflexión sobre el derecho. No basta responder a la pregunta sobre el derecho, expresando que éste puede sintetizarse en un conjunto de normas establecidas y promulgadas por el legislador y por los actos previstos 0 exigidos por ellas, es decir desde una descripción morfológica. Lo mismo sucede desde una mera descripción estructural donde el derecho consiste en un imperativo que prescribe cierto comportamiento (de hacer o no hacer) y prevé una sanción en el caso que se infrinja.

Para responder el interrogante ¿Qué es el derecho? no puedo responder tan solo desde como es éste, resulta insuficiente demostrar que el derecho tiene tal forma y estructura ciertamente conocible, pero mostrada como un objeto separado del hombre y de su existencia.

\footnotetext{
33 Un artículo que explica aproximación del derecho se puede encontrar en SANTA MARIA D'ANGELO RAFAEL, La reflexión jurídica de Sergio Cotta y su aporte al derecho contemporáneo, Universidad Católica San Pablo. I Congreso Internacional de Filosofía del Derecho: "La relación entre el derecho y la moral en el debate iusfilosófico contemporáneo" (17-19 de Junio del 2009), Arequipa 2010. Pp. 331-350.

${ }^{34} \mathrm{Si}$ bien es limitado no niega esta capacidad de razonar propia del hombre, la cual si es rechazada por el filósofo americano Richard Rorty, quien sostiene: "Para superar esta idea en sentido peculiar de obligación moral, sería útil dejar de preguntar "qué nos hace diferentes de los otros animales" y dejar de decir que la diferencia radica en que nosotros podemos pensar mientras que ellos tan sólo pueden sentir. Deberíamos pensar más bien que nosotros podemos sentir los unos por los otros mucho más que ellos. Esto nos permitiría separar la idea cristiana de que el amor importa más que el conocimiento y la idea neoplatónica de que el conocimiento de la verdad nos hará libres. Pues en tanto pensemos que hay un poder ahistórico que tiende a lo justo, un poder llamado
}

Por ello es que se hace inevitable investigar su porqué, conocer el fin al que sirve, esto supera su conocimiento más allá de la simple descripción. Adicionalmente, la cuestión del "porque" no busca únicamente su causa final, sino también la causa originaria del fenómeno en consideración.

De acuerdo a estas consideraciones, al emprender una investigación sobre la interrogante del derecho, si pretendemos ser exhaustivos, tendremos que considerar cuatro niveles: la forma externa o morfológica; la forma interna o estructura; la causa final o función, y finalmente la causa originaria. Las dos primeras determinan como es el derecho; las siguientes, su por qué33.

La experiencia jurídica representa un punto clave para responder a la cuestión del derecho como causa originaria, y al mismo tiempo muestra esa relación indesligable entre hombre y derecho. Ciertamente esta experiencia no es fin en sí misma, sino medio para lograr una adecuada comprensión del ser del hombre, particularmente, el conocimiento del hombre en su integral humanidad.

Así desde el derecho, la reflexión sobre la persona humana, nos muestra la dimensión existencial del derecho. De allí que no es difícil constatar que el hombre es un ser limitado, su experiencia existencial y jurídica destacan esa limitación, tanto de sus capacidades personales, del poder de hacer, entender y juzgar $^{34}$.

El hombre además es un ser finito, esta constatación la experimenta el hombre desde siempre, de allí la necesidad de prolongar el tiempo ${ }^{35}$.

El ser humano es un ser en relación, existir para todo hombre es co-existir, vivir juntos. Resulta imposible negar esto en el ser humano, pues sin esta

verdad o racionalidad, no podremos superar el fundacionalismo... Es el resultado de lo que he venido llamando "educación sentimental"... Ahora estamos en condiciones de hacer a un lado los últimos vestigios de la idea de que los seres humanos se distinguen por su capacidad para la razón en lugar de por su capacidad para la amistad y el mestizaje, por la racionalidad rigurosa en lugar de por la sentimentalidad flexible... Estos dos siglos se entienden mejor no como un período de comprensión profunda de la naturaleza de la moralidad o de la racionalidad sino más bien como una etapa en la que ha ocurrido un progreso sorprendentemente rápido de los sentimientos y se ha vuelto mucho más fácil para nosotros movernos a actuar gracias a las historias tristes y sentimentales.." RORTY RICHARD, Derechos Humanos, Racionalidad y Sentimentalidad. Shute Stephen- Hurley Susan, De los derechos humanos- Las conferencias Oxford Amnesty de 1993. Editorial Trotta. Madrid 1998., pp. 58.

35 Esto se expresa bien en la sucesión, las asociaciones, fundaciones, entre otros, cuya característica es durar más allá de la vida de quienes las hicieron surgir. 
consideración el hombre corre el riesgo de encerrarse en su subjetividad ${ }^{36}$.

Por último, el hombre es consciente de su imperfección, de estar privado de algo (es imperfecto), y lo necesita para ser plenamente él mismo (es indigente).

Todo ello nos lleva a constatar en el ser humano su estructura dual, es decir la conciencia de la imperfección encuentra un dinamismo existencial, que tiende a desarrollarse a sí mismo hasta alcanzar la plenitud y perfección capaz de proyectar. Por ello, es que el hombre tiende a la acción, a superar su propia imperfección y realizar su naturaleza integra también del lado de lo infinito, de lo eterno, de lo absoluto.

Ahora bien, esta constatación de la dualidad ontológica del hombre no queda sólo para si mismo, sino que se extiende a la presencia de los demás. En efecto los otros no representan un obstáculo o un impedimento para la realización personal, pues constitutivamente todo ser humano tiene la necesidad de éstos, su propia naturaleza tiende a ser yo-con-el-otro.

El derecho exige necesariamente la simetría, es decir la intercambiabilidad de los sujetos. Aquello que pretendo (de ser o hacer, de tener o rechazar) para mí, no puedo no reconocerlo a cualquier otro en la misma situación, de lo contrario no se tiene derecho.

La simetría implica la paridad ontológica de los entes, lo que nos permiten a su vez relevar la unión inseparable del derecho y la obligación, su reciprocidad ${ }^{37}$.

Todo ello comporta la universalidad de los derechos fundamentales es decir resguarda al hombre en cuanto hombre, más allá de sus determinaciones particulares, la universalidad de los miembros de la familia humana. "Se debe respetar al hombre en aquello que es ontológicamente". Este es el único principio que puede dar razón suficiente de los Derechos del hombre: universales y no derogables ${ }^{38}$.

\footnotetext{
36 “...no es ya el hombre-en-el-mundo, el yo-con-los-demás o, en definitiva, el individuo-en-relación, sino el sujeto en su unidad egocéntrica, en su existencia y voluntad particulares, consideradas autosuficientes y autofundamentadas..." COTTA SERGIO, Las raíces de la violencia. Una interpretación filosófica. EUNSA. Pamplona 1987. Pp. 170. "El hombre comprende la relacionalidad no solo como hecho, sino también como principio constitutivo del ser humano" PALAZZANI LAURA, Introduzione alla Biogiuridica. Ob. Cit. Pp. 90 (traducción personal)

37 "...el recíproco reconocerse como iguales brinda razón del carácter propiamente humano del derecho y de su universalidad. Es intuición antigua que no puede existir relación jurídica entre hombre
}

Tal universalidad de los derechos fundamentales no es dable sin referencia a una ley universal de justicia, que es expresión de la coexistencia ontológica del hombre, aquí los derechos humanos encuentran su fundamento y la posibilidad de una rigurosa determinación objetiva, libre del arbitrio del legislador (y por ello del arbitrio de la sociedad política y de las masas), como de la exorbitante pretensión de poder del sujeto, que se ponga cual soberana medida de todas las $\operatorname{cosas}^{39}$.

\section{Conclusiones}

La necesidad actual de encontrar mecanismos de tutela de los Derechos Humanos lleva previamente a conocer su fundamento antropológico.

La referencia a las bases antropológicas de los Derechos Humanos considera que se debe reconocer y defender al ser humano por aquello que es, sin preferencia a ningún atributo y gradualidad humana.

La inherente dignidad de la persona humana, muestra además de la consideración ontológica propia de toda persona humana, su referencia moral, que ligada a la libertad y al amor, nos permite aproximarnos (sin con ello agotarla) a la verdad de la persona humana, capaz de brindar un mayor fundamento al derecho.

Esto nos ayuda a comprender la coexistencialidad del derecho, que reconociendo en la relacionalidad humana un rasgo fundamental, la cual combina el reciproco reconocimiento y reciprocidad entre derecho y deber, encuentra en la justicia la condición para su universalidad.

Los tiempos actuales exigen una reflexión jurídica capaz de brindarle un rostro humano al derecho, lo cual combina la necesidad de una mayor profundización teórica y al mismo tiempo un adecuado y honesto ejercicio práctico. y animal, porque falta en ellas una paridad ontológica que la haga posible..." D'AGOSTINO FRANCESCO, Diritto e Giustizia, Edizioni San Paolo. Torino 2000. Pp. 11 (traducción personal)

${ }^{38} \mathrm{Cfr}$. COTTA SERGIO, Conoscenza e normatività. Una prospettiva metafisica. COTTA SERGIO (a cura), Conoscenza e normatività. II Normativo tra deciscione e fondazione. Giuffrè Editore. Milano 1995. Pp. 9- 13.

${ }^{39} \mathrm{Cfr}$. IDEM, Il fondamento dei diritti umani. CONCETTI GINO, I diritti umani. Dottrina e prassi. Editrice AVE. Roma 1982. Pp. 645654. 